\title{
POLA PENYEBARAN TUMBUHAN KANTONG SEMAR (NEPENTHES) DI KAWASAN HUTAN SULTAN DAULAT KOTA SUBULUSSALAM PROVINSI ACEH.
}

\author{
DISTRIBUTION PATTERNS OF NEPENTHES IN THE SULTAN DAULAT FOREST \\ AREA, SUBULUSSALAM CITY, ACEH PROVINCE.
}

\author{
Idawati Payung1, Ekariana ${ }^{2}$, Elfrida ${ }^{3}$ \\ Prodi pendidikan biologi Fakultas Keguruan dan Ilmu Pendidikan \\ Universitas Samudra. \\ Email: idawatipayung25@gmail.com
}

\begin{abstract}
ABSTRAK
Kantong Semar (Nepenthes) tergolong tumbuhan karnivora yang dapat di temukan di beberapa hutan di Indonesia dengan beragam bentuk.Keunikan tumbuhan ini berasal dari kantong yang di modifiaksi oleh daun sebagai mekanisme pertahanan diri untuk mendapatkan makanan. Kawasan hutan Sultan Daulat Kota Subulusaalam Provinsi Aceh tepatnya di perbukitan yang di tumbuhi paku resam yang menjadi salah satu habitat dari tumbuhan Kantong Semar (Nepenthes). Penelitian ini penting di lakukan karena belum adanya data mengenai tumbuhan Kantong Semar (Nepenthes) di daerah tersebut.Penelitian ini di lakukan pada bulan Januari 2021 yang bertujuan untuk mengidentifikasi tumbuahn Kantong Semar (Nepenthes) serta pola penyebarannya. Penelitian ini mengguanakan metode survey eksploratif yaitu dengan cara jelajah langsung dan penentuan jalur pengamatan mengguanakan jalut transek senanyak 5 transek, tiap transek di buat 5 plot, luas plot pengamatan $20 \times 20 \mathrm{~m}$ yang ditempatkan secara purposif sampling. Hasil penelitian di temukan 4 spesies tumbuhan Kantong Semar (Nepenthes), yaitu: Nepenthes ampullaria 51 individu, Nepenthes gracilis 143 individu, Nepenthes mirabilis 171 individu, dan Nepenthes reinwardtiana 98 indidu. Pola penyebaran tumbuhan Kantong Semar (Nepenthes) di kawasan hutan Sultan Daulat yang di uji dengan Standart Indeks Morisita Ip $>0$ menunjukkan pola penyebaran tergolong mengelompok (Clumped).
\end{abstract}

Kata kunci: Kantong Semar (Nepenthes), purposif sampling, survey eksploratif, kota subulussalam.

\begin{abstract}
ABSTACT
Nepenthes is classified as a carnivorous plant that can be found in several forests in Indonesia with various forms. The uniqueness of this plant comes from the bag that is modified by leaves as a self-defense mechanism to get food. The forest area of Sultan Daulat, Subulusaalam City, Aceh Province, precisely in the hills overgrown with ferns, is one of the habitats of the Nepenthes plant. This research is important to do because there is no data regarding the Nepenthes in the area. This research was carried out in January 2021 which aims to identify the Nepenthes and its distribution pattern. This research uses an exploratory survey method, namely by direct exploration and determining the observation path using a total of 5 transects, each transect is made of 5 plots, the area of observation plots is $20 \times 20 \mathrm{~m}$ which is placed purposively sampling. In this research the researcher found there are 4 species of Nepenthes such as: Nepenthes ampullaria 51 individuals, Nepenthes gracilis 143 individuals, Nepenthes
\end{abstract}


mirabilis 171 individuals, and Nepenthes reinwardtiana 98 individuals. The distribution pattern of Nepenthes in the forest area of Sultan Daulat which was tested with the Morisita Standard Index Ip > 0 showed the distribution pattern was classified as clustered (Clumped).

\section{Keyword : Nepenthes, purposif sampling, survey eksploratif, kota subulussalam.}

\section{PENDAHULUAN}

Tumbuhan kantong semar (Nepenthes) termasuk sekelompok tumbuhan epifit berhabitus herba yang biasanya sering dijumpai pada kawasan yang tidak subur dengan kandungan unsur hara yang rendah seperti kandungan tanah $\mathrm{N}$, $\mathrm{P}$, dan $\mathrm{K}$, tanah masam dengan $\mathrm{pH}$ tanah berkisar 2- 4,5, dan kelembapan yang tinggi (Mardhiana, 2012). Indonesia, Malaysia, dan Philipina merupakan daerah yang paling luas persebaran tumbuhan kantong Semar (Nepenthes) karena negara tersebut termasuk kedalam kawasan Asia Tenggara dengan ciri-ciri hutannya identik dengan hutan hujan tropis (Cahyono, 2019).

Kota Subulussalam merupakan salah satu kota di Provinsi Aceh. Kota Subulussalam merupakan daerah yang miskin unsur hara di tinjau dari keadaan unsur tanah yang ada di kota Subulussalam. Namun ada jenis tumbuhan yang hidup didaerah yang miskin unsur hara biasa ada tumbuhan yang mendominasi sebagai habitat untuk tumbuh dan berkembang. Kota Subulussalam merupakan daerah yang luas pengembangan tanaman kelapa sawit, hampir seluruh hutan Kota Subulussalam sudah menjadi lahan perkebunan PT kelapa sawit, hal ini mengakibatkan hilangnya beberapa jenis tanaman yang ada di daerah itu. Berdasarkan hal inilah peneliti melalukan peneltian dikota Subulussalam karena di Kota Subulussalam Provinsi Aceh belum ada laporan atau penelitian tentang tumbuhan kantong semar (Nepenthes).

\section{METODOLOGI}

Penelitian dilaksanakan pada bulan Januari 2021 dikawasan hutan sultan daulat. Alat dan bahan yang digunakan Soil tester, Thermometer, Meteran, Patok kayu, Parang, Kamera, Alat tulis, Buku trubus infokit Nepenthe, Alkohol 70\%, Alat press, Tali plastik, dan Kertas label. Penentuan metode penelitian menggunakan metode jalur/transek garis, yang dilettakan menggunakan metode purpossive 
sampling berdasarkan rona lingkungan (Jeffri dkk, 2017).

Pengamatan tumbuhan Kantong Semar (Nepenthes) menggunakan metode jelajah di jalur penelitian yang dibuat menggunakan metode sampling plot dengan membuat petak ukur berukuran $20 \mathrm{~m} \times 20 \mathrm{~m}$. Tumbuhan Kantong Semar (Nepenthes) yang ditemukan di areal pengamatan,hal pertama yang dilakukan mengambil dokumentasi gambar dengan menggunakan kamera digital, tumbuhan Kantong Semar (Nepenthes) yang dijumpai diidentifikasi langsung dengan menggunakan buku "Trubus Infokit Nepenthes", tumbuhan yang di jumpai dicatat jumlahnya dan diamati karakteristik morfologinya, karakteristik morfologi yang diamati adalah bentuk daun, bentuk kantong, bentuk batang, ukuran batang, ukuran kantong, ukuran daun, warna daun, warna batang, warna kantong, panjang sulur, dan lainnya yang membedakan antar setiap spesies (Mardhiana, 2012).

Untuk mengetahui pola penyebaran tumbuhan kantong semar berdasarkan tempat tumbuh tumbuhan kantong semar (Nepenthes), kelembapan tanah, kelembapan udara, suhu dan $\mathrm{pH}$ tanah. Pola penyebaran dihitung menggunakan indeks morisitas yang telah distandarisasi yang dinyatakan dalam rumus sebagai berikut:

$$
I d=n \frac{\left(\Sigma x^{2}-\Sigma x\right)}{(\Sigma x)^{2}-\Sigma x}
$$

\section{Keterangan:}

Id : Derajat penyebaran morisita

$\mathrm{N} \quad$ : Jumlah petak ukur

$\Sigma \mathrm{x}^{2} \quad$ : Jumlah kuadrat dari total individu suatu spesies pada suatu komunitas

$\Sigma \mathrm{x}$ : Jumlah total individu suatu spesies pada suatu komunitas

Uji derajat keseragaman

$$
\mathrm{Mu}=\frac{\mathrm{X}^{2} 0,975-\mathrm{n}+\Sigma \mathrm{Xi}}{(\Sigma \mathrm{Xi})-1}
$$

Derajat pengelompokan

$$
\mathrm{Mc}=\frac{\mathrm{X}^{2} 0,025-\mathrm{n}+\Sigma \mathrm{Xi}}{(\Sigma \mathrm{Xi})-1}
$$

Standar derajat morisita (Ip)

$$
\mathrm{Ip}=0,5+0,5\left(\frac{\mathrm{Id}-\mathrm{Mc}}{\mathrm{n}-\mathrm{Mc}}\right)
$$

Standart Derajat Penyebaran Indeks Morisita (Ip) mempunyai interval -1,0-1,0 dengan tingkat kepercayaan $95 \%$ pada batasan 0,5 dan $-0,5$. Nilai Ip digunakan agar menunjukkan kecenderungan pola penyebaran spesies tumbuhan Kantong Semar (Nepenthes) pada suatu 
komunitas tumbuhan dikawasan hutan

Sultan Daulat dengan rentang nilai jika:

$$
\text { Ip }=0=\text { Pola penyebaran acak }
$$

(Random)

$$
\text { Ip }>0=\text { Pola penyebaran }
$$

Mengelompok (Clumped)

Ip $<0=$ Pola penyebaran merata

\section{(Uniform)}

Untuk kebenaran berkelompok atau tidak harus dilakukan uji lanjutan dengan rumus distribusi chi-squere:

$$
\mathrm{X}^{2}=\left(\mathrm{n} \sum \mathrm{X}^{2} / \mathrm{N}\right)-\mathrm{N}
$$

Sugianto menyatakan jika nilai $\mathrm{X}^{2}$ hitung dibandingkan dengan nilai $\mathrm{X}^{2}$ tabel dengan derajat bebas $(\mathrm{df}=\mathrm{n}-1)$. Jika $X^{2}$ hitung $<X^{2}$ tabel maka di katakan bahwa bentuk pola penyebarannya tidak beda nyata dengan
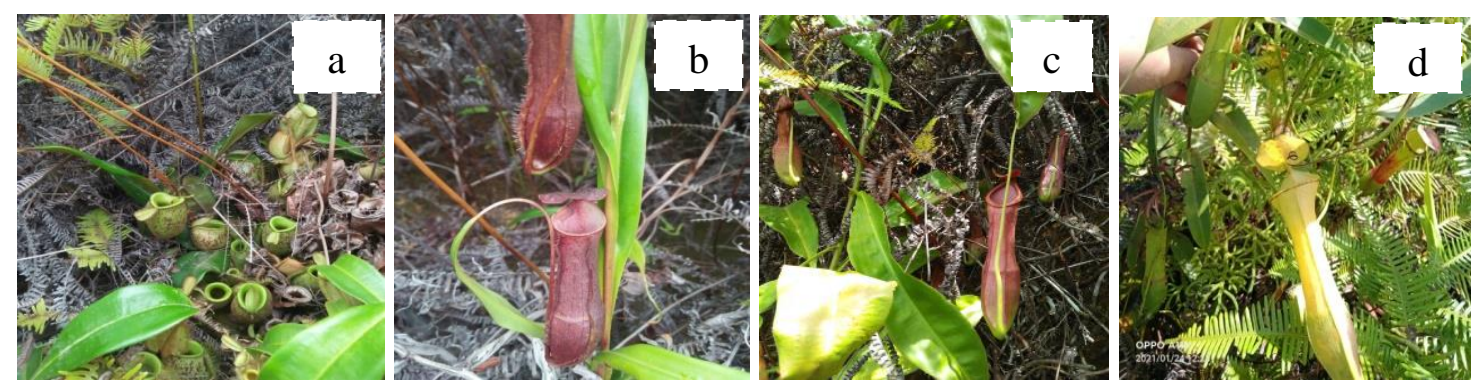

Gambar 1: a. Nepenthes ampullaria, b. Nepenthes gracilis, c. Nepenthes mirabilis, d. Nepenthes reinwardtiana.

\section{Pola penyebaran}

Pola penyebaran merupakan penyebaran individu-individu populasi secara horizontal pada suatu habitat. Pola penyebaran terbagi menjadi tiga, secara acak (random), Seragam pola penyebaran berkelompok. Jika $\mathrm{X}^{2}$ hitung $>\mathrm{X}^{2}$ tabel maka dapat di katakan bahwa bentuk pola penyebatan berbeda nyata dengan pola penybaran berkelompok.

\section{HASIL DAN PEMBAHASAN}

Hasil penelitian tumbuhan Kantong Semar (Nepenthes) yang ditemukan dikawasan hutan Sulatan Daulat dengan tipe bertebing yang ditumbuhi penuh dengan paku resam yaitu: Nepenthes ampullaria 51 individu, Nepenthes gracilis 143 individu, Nepenthes mirabilis 171 individu, dan Nepenthes reinwardtiana 98 individu. 
Tabel 1 Pola penyebaran tumbuhan Kantong Semar (Nepenthes)

\begin{tabular}{lllcclcccc}
\hline No & \multicolumn{1}{c}{ Nama } & \multicolumn{1}{c}{$\boldsymbol{\Sigma} \mathbf{X}^{\mathbf{2}}$} & $\mathbf{N}$ & $\mathbf{I p}$ & $\mathbf{X}_{\text {hitung }}$ & $\mathbf{D b}$ & $\mathbf{A}$ & $\mathbf{X}^{\mathbf{2}}$ Tabel & Kriteria \\
\hline $\mathbf{1}$ & N. ampullaria & 512 & 25 & 0,53 & 199,98 & 24 & 0,05 & 36,41 & Mengelompok \\
$\mathbf{2}$ & N. gracilis & 1265 & 25 & 0,51 & 78,15 & 24 & 0,05 & 36,41 & Mengelompok \\
$\mathbf{3}$ & N. mirabils & 1898 & 25 & 0,51 & 106,48 & 24 & 0,05 & 36,41 & Mengelompok \\
$\mathbf{4}$ & N. reinwardtiana & 1060 & 25 & 0,51 & 172,41 & 24 & 0,05 & 36,41 & Mengelompok \\
\hline
\end{tabular}

Dalam penelitian ini pola penyebaran tumbuhan Kantong Semar (Nepenthes) dapat diketahui berdasarkan indeks morisita yang di uji dengan standart derajat morisita bahwa Ip > 0 yang artinya pola penyebaran mengelompok (Clumped). Pola penyebaran mengelompok di pengaruhi oleh banyak faktor diantaranya faktor fisika-kimia atau kondisi lingkungan tempat tumbuhnya tumbuhan hal ini sesuai dengan perkataan (Kucler, 1967) dalam (Mondiana, 2018) organisme disuatu tempat bersifat saling bergantung, dan tidak berkaitan berdasarkan kesempatan semata, dan apabila terjadi gangguan maka akan berpengaruh terhadap komunitas.

Penyebaran Kantong Semar (Nepenthes) dikawasan hutan Sultan Daulat tergolong berkelompok karena hampir disetiap transek pengamatan di temukan semua spesies, hal ini karena keempat spesies yang di temukan biasanya tumbuh pada habitat tanah berbatu dan berpasir, dimana tanah ini hara (Santoso, 2006). Tanah ini sesuai dengan jenis tanah yang ada di daerah hutan Sultan Daulat. Salah satu jenis tanah yang terdapat di kawasan hutan Sultan adalah Jenis tanah Podsolik Merah Kuning (PMK) memiliki karakteristik keadaan tekstur tanah liat, porositas jelek dan mudah larut. Kandungan bahan organik pada jenis tanah ini hanya sekitar $10 \%$, serta memiliki kandungna unsur hara yang rendah sangat baik untuk di tumbuhi oleh jenis tumbuhan Kantong Semar (Nepenthes) dan beberapa tumbuhan lainnya seperti tumbuhan anggrek dan paku-pakuan (Siffa, 2019).

Penyebaran yang paling banyak dijumpai adalah Nepenthes mirabilis hal ini karena Nepenthes mirabilis merupakan jenis spesies yang sifat hidupnya lebih menyukai daerah yang terbuka dan banyak mengandung air, Hal ini sesuai dengan hasil penelitian Adi Bejo Suawdi dan Zidni, bahwa faktor lingkungan memberikan pengaruh yang besar dalam menentukan 
jumlah dan jenis Kantong Semar (Nepenthes) yang hidup pada suatu daerah tempat tumbuhannya. Sedangkan spesies yang paling sedikit di jumpai adalah Nepenthes amupullaria hal ini karena spesies ini hanya mampu tumbuhan dengan baik pada daerah yang lembab.
Faktor fisika - kimia.

Tumbuhan Kantong Semar (Nepenthes) dapat tumbuh dan berkembang di hutan Sultan Daulat Kota Subulussalam dipengaruhi oleh kondisi faktor fisika - kimia hutan tersebut. Faktor fisika - kimia dapat dilihat pada tabel berikut:

Tabel 2 Kondisi faktor fisika - kimia dilokasi penelitian

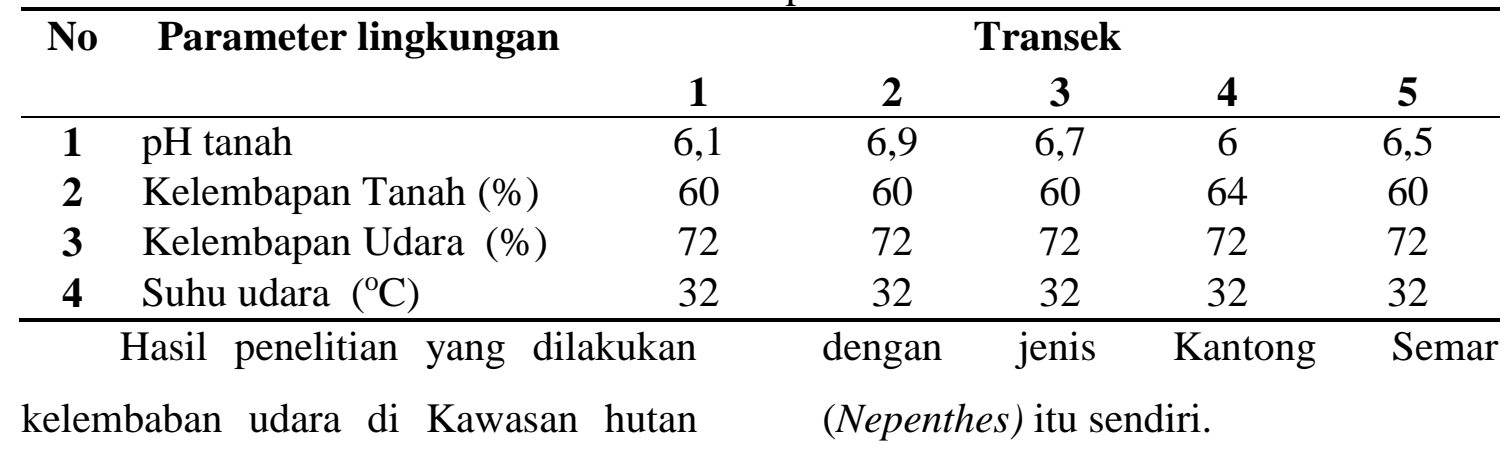

Sultan Daulat rata-rata (72\%), sushu

udara $\left(32{ }^{\circ} \mathrm{C}\right)$, kelembapan tanah (62$64 \%)$, pH tanah $(6-6,9)$. Hal ini sesuai dengan hasil penelitian Jeffri dkk, bahwa kondisi faktor fisika-kimia sangat berpengaruh dalam pertumbuhan Kantong Semar (Nepenthes) dengan hasil pengukuran kelembaban berkisar 78-82\%, sedangkan suhu berkisar 25-26 ${ }^{\circ} \mathrm{C}$, pada umumnya tumbuhan Kantong Semar (Nepenthes) dapat tumbuh dengan baik pada suhu $25-32{ }^{\circ} \mathrm{C}$ dan kelembapan berkisar anatara 70-85 \%. Pada umumnya suhu, kelembaban, dan

\section{KESIMPULAN}

Berdasarkan hasil penelitian yang dilakukan dikawasan hutan Sultan Daulat ditemukan 4 jenis tumbuhan Kantong Semar (Nepenthes) yaitu, Nepenthes ampullaria, Nepenthes gracilis, Nepenthes mirabilis, dan Nepenthes reinwardtiana. Pola penyebaran tumbuhan Kantong Semar (Nepenthes) dikawasan hutan Sultan Daulat memiliki nilai Indek Morisita yaitu Ip > 0 maka pola penyebarannya adalah mengelompok (Clumped).

$\mathrm{pH}$ untuk partumbuhan kantong semar (Nepenthes) berbeda-beda tergantung 
SARAN

Saran dari peneliti perlu adanya penelitian lanjutan di Kota Subulussalam Provinsi Aceh serta mengenai simbiosis mutualisme keberadaan serangga pada setiap jenis kantong semar, dan juga mengenai perbedaan jenis serangga yang terperangkap di dalam kantong atas dan didalam kantong bawah. Contoh serangga yang terdapat di dalam kantong bawah seperti Semut, Lalat ddl. Sedangkan contoh jenis serangga yang masuk didalalam kantong atas seperti, Nyamuk, Laba-Laba dan Lebah.

\section{DAFTAR PUSTAKA}

Budi Santoso., "Pemberdayaan Lahan Podzolik Merah Kuning Dengan Tanaman Rosella (Hibiscus Sabdariffa) di Kalimantan Selatan", Jurnal Litbang Pertanian, Vol.5, No.1, (2006), h.14.

Cahyono, didi budi, dkk.2019. Karakteristik Habitat Tumbuhan Kantong Semar (Nepenthes sp) Di Pulau Halmahera. Jurnal penelitian. 8 (1) : 233-241.

Http://Sippa.Ciptakarya.Pu.Go.Id/Sippa _Online/Ws_File/Dokumen/Rpi
2jm/DOCRPI2JM_3574004b62 _BAB\%20VIBAB\%206..Pdf.

Jeffri, dkk. 2017. Keanekaragaman Jenis Kantong Semar (Nepenthes spp) di Kawasan Pelestarian Plasma Nutfah (KPPN) PT. Muara Sungai Landak Kabupaten Mempawah. Jurnal protobiot. 6 (3) : 42-50.

Mansur, M. 2006. Nepenthes, Kantong Semar yang Unik. Jakarta, Penebar Swadaya.

Mardhiana, dkk. 2012. Karakteristik dan Kelimpahan Nepenthes dihabitat Miskin Unsur Hara. Jurnal Lahan Suboptional.1(1): 50-56.

Suwardi, A., B. Navia, Z., I. 2015. Keanekaragaman Jenis Kantong Semar (Nepenthes spp.) Di Hutan Rawa Gambut Kalimantan Barat.Jurnal Jeumpa. 2 (2): 56-63.

Syamsi, F. Destaria. 2017. Keanelaragaman kantong semar (Nepenthes spp) di Pulau Batam. Jurnal Dimensi. 6 (3) : 442-452.

Susilawati, dkk. 2016. Pengaruh Berbagai Intesitas Cahaya Terhadap Pertumbuhan Semai Cempaka (Michelia champaca L.) di Persemaian. Jurnal Forest Sains. 14 (1) : 59-66. 